\title{
Gastrin Releasing Peptide Is a Selective Mitogen for Small Cell Lung Carcinoma In Vitro
}

\author{
Steven Weber, Joan E. Zuckerman, David G. Bostwick, Klaus G. Bensch, Branimir I. Sikic, and Thomas A. Raffin
}

Departments of Medicine and Pathology, Stanford University School of Medicine, Stanford, California 94305

\begin{abstract}
Human small cell lung carcinoma (SCLC) cells have been shown to contain significant levels of a bombesin-immunoreactive peptide. The 27 -amino acid peptide, gastrin releasing peptide (GRP), has recently been shown to be responsible for the bombesin-like immunoreactivity found in SCLC cells. Among four lung cancer cell lines examined in vitro, GRP exhibited mitogenic activity for two SCLC subtypes, but not for a squamous carcinoma or adenocarcinoma lung cell line. The mitogenicity of the GRP molecule has been isolated to the carboxyterminal fragment, designated GRP 14-27, which is in part homologous to bombesin. The aminoterminal fragment, GRP 1-16, is not homologous to bombesin and exhibits no mitogenic activity. Thus, GRP may be an important growth regulating or autocrine factor in human SCLC.
\end{abstract}

\section{Introduction}

The production of self-stimulatory, or autocrine, growth factors by cancer cells has been postulated to play a role in the abnormal growth regulation characteristic of malignant cells. Bombesin, a tetradeca-peptide originally isolated from amphibian skin (1), exhibits biological activity in mammals, ranging from the stimulation of smooth muscle contraction and hormone secretion to alteration of body temperature and behavior (2). Bombesin has also been shown to be mitogenic for both Swiss 3T3 fibroblasts and human bronchial mucosal cells in vitro, probably via interaction with specific cell surface receptors in a manner similar to platelet-derived growth factor, epidermal growth factor, and insulin $(3,4)$. The demonstration of significant levels of bombesin-like immunoreactivity in human small cell lung carcinoma (SCLC) ${ }^{1}$ (5) suggests that a bombesin-like peptide might exert a self-stimulatory effect on these tumors through an autocrine mechanism. It has recently been shown that gastrin releasing peptide (GRP), a 27-amino acid peptide originally isolated from porcine intestine, is the

Address correspondence to Dr. Raffin, Department of Medicine, Stanford University Medical Center, Stanford, CA 94305.

Received for publication 7 August 1984 and in revised form 9 October 1984.

1. Abbreviations used in this paper: FCS, fetal calf serum; GRP, gastrin releasing peptide; $\left[{ }^{3} \mathrm{H}\right]$ thy, $\left[{ }^{3} \mathrm{H}\right]$ thymidine; $P D G F$, platelet-derived growth factor; SCLC, small cell lung carcinoma.

J. Clin. Invest.

(c) The American Society for Clinical Investigation, Inc.

0021-9738/85/01/0306/04 \$1.00

Volume 75, January 1985, 306-309 mammalian analog of bombesin (6). The carboxyterminal fragment, GRP 14-27, exhibits significant sequence homology to bombesin, while the aminoterminal fragment, GRP 1-16, does not. This study examines the mitogenic effect of GRP (Fig. 1) and its various peptide fragments in human SCLC and the other histologic subtypes of lung cancer.

\section{Methods}

Cell culture. Two human SCLC cell lines, NCI-H128 and NCI-H69 (obtained from Dr. D. Carney, National Institutes of Health), were maintained in culture in either RPMI-1640 medium with $10 \%$ fetal calf serum (FCS; Gibco Laboratories, Long Island, NY) or in serumfree HITES (hydrocortisone, insulin, transferrin, 17-B-estradiol, and selenium) medium as previously described (7), supplemented with $10 \mathrm{U}$ penicillin/ml and $10 \mu \mathrm{g}$ streptomycin per milliliter. Electron microscopy was performed on SCLC cells to document presence or absence of neurosecretory-like granules. Lung cell lines CALU-3 (human adenocarcinoma) and SK-MES-1 (human squamous carcinoma) (both obtained from American Type Tissue Collection, Rockville, MD), were maintained in culture in Eagle's Minimal Essential Medium with Earle's Salts, containing 10\% FCS and antibiotics as described above.

Mitogenicity assays. All cell lines were harvested at confluence. $6 \times 10^{3}$ cells were added to individual wells of 96-well plates in 0.18 $\mathrm{ml}$ of growth medium as noted containing $10 \%$ FCS supplemented with penicillin and streptomycin. GRP, GRP 14-27, and GRP 1-16 (Peninsula Laboratories, Inc., Belmont, CA), were added separately to the wells in $0.02 \mathrm{ml}$ of serum-free balanced salt solution to achieve proper final concentrations in the wells. Control samples for each cell line consisted of wells to which $0.02 \mathrm{ml}$ of balanced salt solution without peptides was added. After $36 \mathrm{~h}$ of incubation at $37^{\circ} \mathrm{C}$ in a humidified atmosphere of $5 \% \mathrm{CO}_{2}$ and air, $0.4 \mu \mathrm{Ci}$ of $\left[{ }^{3} \mathrm{H}\right]$ thymidine $\left({ }^{3} \mathrm{H}\right]$ thy; New England Nuclear, Boston, MA) was added to each well along with nonradioactive thymidine in $0.02 \mathrm{ml}$ of balanced salt solution to achieve a final thymidine concentration of $10^{-4} \mathrm{M}$. After an additional $20 \mathrm{~h}$ of incubation, the cells were collected onto glass fiber filters with a cell harvester (Cambridge Technology, Inc., Cambridge, MA), and DNA was precipitated with ice-cold TCA. $\left[{ }^{3} \mathrm{H}\right] \mathrm{Thy}$ incorporation into acid-insoluble fractions of DNA was determined by liquid scintillation counting using a series counter (9000; Beckman Instruments, Inc., Fullerton, CA) and was used as a measure of cell proliferation. Results were expressed as percent of dpm measured in control wells of each cell line. All values are expressed as the mean \pm SEM of six cultures.

To confirm results observed with the $\left[{ }^{3} \mathrm{H}\right]$ thy incorporation assay, $1 \times 10^{6}$ cells $(\mathrm{NCI}-\mathrm{H} 69)$ were seeded in T25 flasks in $7 \mathrm{ml}$ of standard culture medium or medium supplemented with GRP at $10 \mu \mathrm{g} / \mathrm{ml}$. After 24, 48, and $72 \mathrm{~h}$ of incubation, flasks were harvested and the number of viable cells within the flasks was determined using trypan blue exclusion on a standard hemocytometer. Both the cells that had been exposed to GRP and those that had not were then reseeded at equal densities in GRP-free medium, to determine if the observed mitogenic effect of GRP was or was not reversible upon removal of cells from immediate contact with the peptide. 


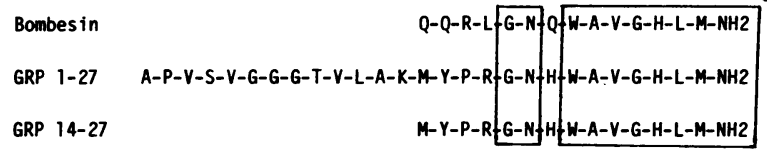

GRP 1-16 A-P-V-S-V-G-G-G-T-V-L-A-K-M-Y-P

Figure 1. Amino acid sequences of the peptides bombesin, GRP 127, GRP 14-27, and GRP 1-16. Significant sequence homology is seen for bombesin, GRP 1-27, and the carboxyterminal fragment GRP 14-27. The aminoterminal fragment GRP 1-16 bears no homology to bombesin.

\section{Results}

Electron micrographs of small cell lung cancer cells showed the tumor cell cytoplasm to contain scattered uniform neurosecretory-like granules.

Incorporation of $\left[{ }^{3} \mathrm{H}\right]$ thy into both NCI-H128 and NCI$\mathrm{H} 69$ cells (SCLC lines) was significantly increased by exogenous administration of low levels of the complete molecule GRP 1-27 (Fig. 2). A GRP 1-27 level of $10 \mu \mathrm{g} / \mathrm{ml}$ produced a 150 $200 \%$ increase in $\left[{ }^{3} \mathrm{H}\right]$ thy incorporation in both SCLC lines. However, there was no mitogenic effect of the complete molecule on the adenocarcinoma or squamous cell lung carcinoma lines.

The bombesin-homologous fragment GRP 14-27 at a level of $5 \mu \mathrm{g} / \mathrm{ml}$ produced a $250-300 \%$ increase in $\left[{ }^{3} \mathrm{H}\right]$ thy incorporation in both small cell lines. Also, at higher doses, there seemed to be some increase in $\left[{ }^{3} \mathrm{H}\right]$ thy incorporation due to GRP 14-27, which was not the case with GRP 1-27. GRP 14-27 had no mitogenic effect on the adenocarcinoma or squamous cell lung carcinoma lines.
The aminoterminal fragment, GRP 1-16, which does not exhibit significant sequence homology to bombesin, had no mitogenic effect on any of the cell lines tested.

The mitogenic effect of GRP and its carboxyterminal fragment in SCLC in vitro exhibited a dose-response effect with a narrow range of effective concentrations. Note that the stimulatory effect of GRP 14-27 on SCLC decreased at concentrations higher than $5 \mu \mathrm{g} / \mathrm{ml}$ (Fig. 3). Maximal (threefold) stimulation by GRP 14-27 occurred at a concentration approximately equimolar to the concentration of GRP 1-27, which produced maximal stimulation.

Cell number as determined by hemocytometer counting revealed a mitogenic effect of GRP upon SCLC cells, confirming the observations made by $\left[{ }^{3} \mathrm{H}\right]$ thy incorporation. After $24 \mathrm{~h}$, GRP at a level of $10 \mu \mathrm{g} / \mathrm{ml}$ caused a $170 \%$ increase in the proliferation of NCI-H69 cells. After $48 \mathrm{~h}$ and again after 72 $h$, an increase of $270 \%$ in cell number was measured in the cells that had been exposed to GRP, compared with those that had not been exposed (Fig. 4).

When SCLC cells previously exposed to GRP were removed from the peptide and reseeded in GRP-free medium, they no longer proliferated at an increased rate. After 24, 48, and 72 $h$ of incubation in standard medium, cells that had previously been exposed to GRP proliferated at a rate equivalent to those that had not been exposed, demonstrating the reversibility of the mitogenic effect.

\section{Discussion}

$\sim 25 \%$ of all lung cancers are classified as SCLC. Clinically, SCLC is distinguished from "non-small cell" lung cancers by its characteristic cellular morphology, a tendency to metastasize
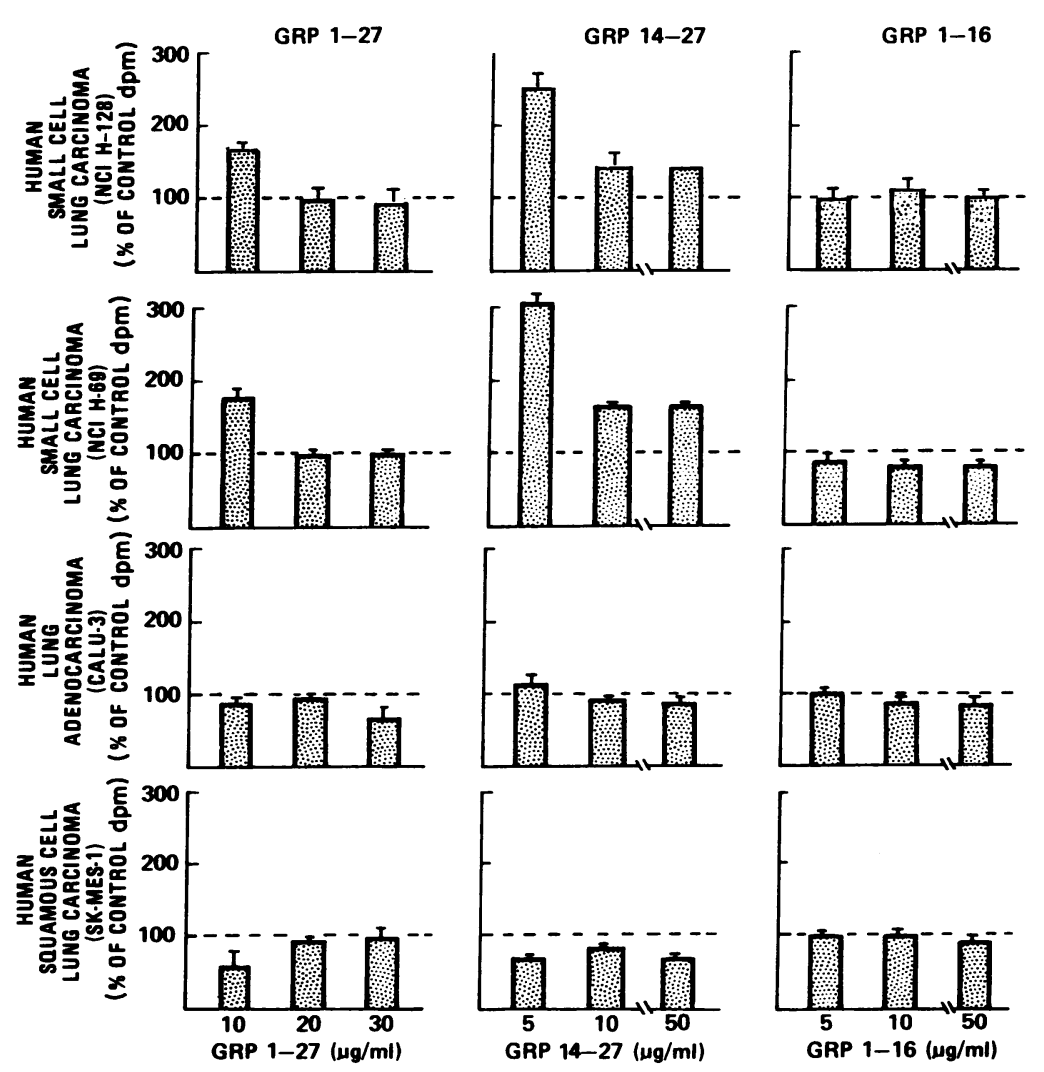

Figure 2. Mitogenic effects of GRP 1-27, GRP 14-27, and GRP 1-16 on four human lung cancer cell lines in vitro. The data represent $\left[{ }^{3} \mathrm{H}\right]$ thy incorporation into TCA-precipitable DNA, expressed as percent of dpm measured in control wells. Results obtained at concentrations of GRP $1-27$ at $50 \mu \mathrm{g} / \mathrm{ml}$ and $100 \mu \mathrm{g} / \mathrm{ml}$, and of GRP $14-27$ and GRP $1-16$ at $25 \mu \mathrm{g} / \mathrm{ml}, 75 \mu \mathrm{g} / \mathrm{ml}$, and $100 \mu \mathrm{g} / \mathrm{ml}$ were consistent with the data shown. These additional points have been omitted from the figure for clarity. All values represent the mean $\pm S E M$ of six cultures. 


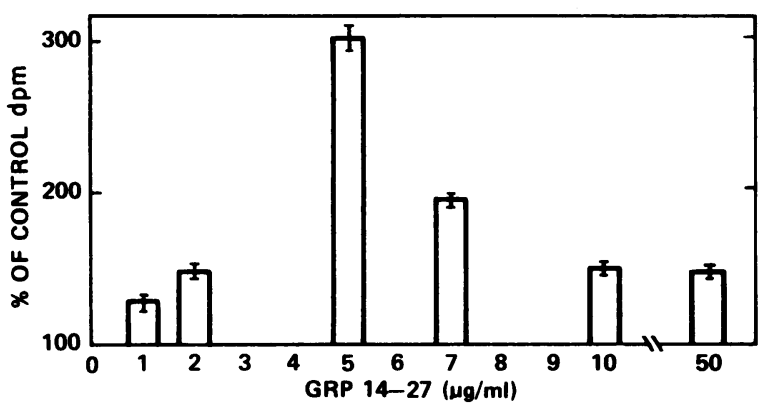

Figure 3. Mitogenic effect of GRP 14-27 on SCLC cell line NCIH69. Note peak (threefold) stimulation at concentration of $5 \mu \mathrm{g} / \mathrm{ml}$. Equivalent peptide concentrations did not produce stimulation of $\left[{ }^{3} \mathrm{H}\right]$ thy incorporation by the non-SCLC cell lines studied. Values represent the mean \pm SEM of six cultures.

rapidly and widely, its responsiveness to chemotherapy, and its frequent association with various paraneoplastic syndromes (8). Biologically, SCLC is of interest in that it shares numerous cellular features with neuroendocrine cells of the respiratory epithelium (9). SCLC cell lines are characterized by the presence of neurosecretory granules, high levels of L-dopa decarboxylase, creatine kinase BB (the brain-specific isoenzyme), and neuronspecific enolase, all of which suggest neuroendocrine differentiation of these cells (10). Indeed, the syndromes that can accompany this cancer result from the ectopic production of various neuroendocrine peptides by these cells (10). Some of the peptides that have been found to be secreted by SCLC cells in vivo, in vitro, and in nude mouse xenografts, include ACTH, a calcitonin-immunoreactive peptide, antidiuretic hormone, and a bombesin-immunoreactive peptide (11).

The amphibian peptide bombesin has been demonstrated to act as a mitogen for both Swiss 3T3 fibroblasts and normal human bronchial mucosal cells, suggesting that its mammalian analog, GRP 1-27, may play a role in normal growth regulatory processes $(3,12)$. Bombesin-like immunoreactivity has been consistently demonstrated in SCLC cells both in vitro and in immunohistochemical stains of tissue sections $(4,5)$, but it has rarely been observed in the other major histologic subtypes of lung cancer (5). Furthermore, the bombesin-like immunoreactivity in SCLC originally ascribed to the presence of the amphibian peptide bombesin within SCLC (5) has been found

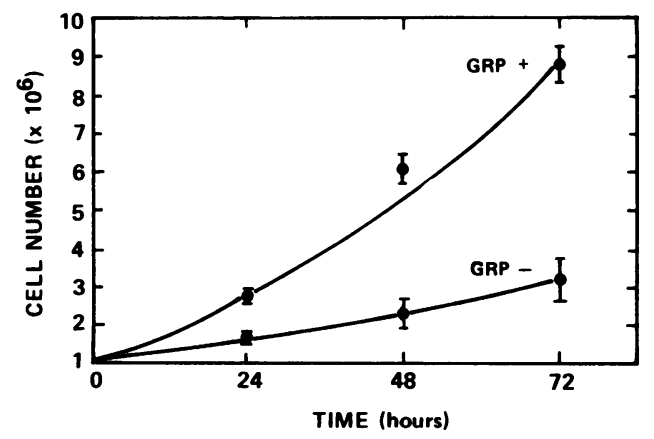

Figure 4. Mitogenic effect of GRP 1-27 on SCLC cell line NCI-H69. The data represent viable cell number as measured by trypan blue exclusion on a standard hemocytometer. Values represent the mean \pm SEM of four cultures. to be attributable to the 27-amino acid peptide GRP 1-27 (6, 13). The possibility that GRP might be involved in the regulation of growth of SCLC led us to examine the mitogenic activity of GRP in these cells.

It has been previously proposed that in some cases, transformed cells may express, maintain, or enhance their malignant phenotype by the secretion of autocrine growth factors, thus enabling a positive feedback loop whereby a cell might both produce and respond to the same hormone (14). Such a system seems to have been observed in a sarcoma cell line that is associated with the synthesis and secretion of a platelet-derived growth factor (PDGF) immunoreactive substance. This transforming growth factor reacts with PDGF antisera, binds to PDGF receptors, and is mitogenic for the cells that produce it (3). Other common hormones and growth factors, such as epidermal growth factor $(15,16)$, have been shown to possess mitogenic and/or transforming properties in vitro. Indeed, it has been suggested that the way a cell responds to common growth factors may play a central role in expression of the malignant phenotype (14).

This study examines the possible role of GRP in SCLC as an autocrine growth factor capable of stimulating the mitogenic proliferation of these cells. We have demonstrated that the neuroendocrine-related SCLC cells, which have previously been shown to contain a bombesin-like immunoreactive peptide, exhibited a mitogenic response to the exogenous administration of GRP 1-27 and the carboxyterminal fragment GRP 14-27, which bears significant homology to bombesin. These same peptides had no effect on the squamous and adenocarcinoma cell lines examined. The aminoterminal fragment GRP 1-16 showed no homology to bombesin and was not mitogenic for any of the cell lines tested. Thus, it seems that GRP or a closely related small peptide may be acting as an autocrine growth factor for SCLC and may play a role in the abnormal growth regulation of these cells in vivo.

The relatively high concentrations of exogenous GRP required to stimulate the proliferation of SCLC cells may be due in part to differences in activity between the synthetic and the natural peptide, or perhaps to differences in concentration at the cell surface. Note that maximal stimulation by both GRP 1-27 and GRP 14-27 occurs at a narrow range of peptide concentrations followed by a decrease in mitogenic stimulation at higher concentrations of peptide. Similar doseresponse curves have been demonstrated for other growth factors and hormones (17), but generally this effect has been seen to occur over a much broader range of concentrations. The decrease in maximal stimulation may result from a negative cooperativity between receptor binding units, a down regulation of receptors, or a receptor desensitization similar to that seen with the acetylcholine receptor; alternatively, GRP may have additional effects at higher concentrations.

\section{Acknowledgments}

We would like to thank Kathy Stephens for her expert secretarial assistance. The two SCLC cell lines were generously provided by Dr. Desmond Carney.

This study was supported by the following grants: The Levi Strauss Foundation, Edna and Jack Patterson Lung Cancer Research Fund, National Institute of General Medical Science (grant GM07781), and American Cancer Society Institutional Research Grant. 


\section{References}

1. Anastasi, A., V. Erspamer, and M. Bucci. 1971. Isolation and structure of bombesin and alytesin: two analagous active peptides from the skin of the European amphibians Bombina and Alytes. Experientia (Basel). 27:166-167.

2. Bloom, S. R., and Polak, J. M., editors. 1981. Gut Hormones. Churchill Livingstone, New York. 534.

3. Stiles, C. D. 1983. The molecular biology of platelet derived growth factor. Cell. 33:653-655.

4. Willey, J. C., J. F. Lochner, and C. C. Harris. 1984. Bombesin and the C-terminal tetradecapeptide of gastrin-releasing peptide are growth factors for normal human bronchial epithelial cells. Exp. Cell Res. In press.

5. Moody, T. W., C. B. Pert, A. F. Gazdar, D. N. Carney, and J. D. Minna. 1981. High levels of intracellular bombesin characterize human small cell lung carcinoma. Science. (Wash. DC). 214:12461248.

6. Brown, M., W. Mark, and J. Rivier. 1980. Is GRP mammalian bombesin? Life Sci. 27:126-128.

7. Carney, D. N., P. A. Bunn, Jr., A. F. Gazdar, J. A. Pagan, and J. D. Minna. 1981. Selective growth in serum-free hormone-supplemented medium of tumor cells obtained by biopsy from patients with small cell carcinoma of the lung. Proc. Natl. Acad. Sci. USA. 78:3185.

8. Greco, A. F., editor. 1981. Small Cell Lung Cancer. Grune and Stratton, New York. 225-235.
9. Gould, V. E., R. I. Linnoila, V. A. Memoli, and W. H. Warren. 1983. Neuroendocrine cells and neuroendocrine neoplasms of the lung. Pathol. Annu. 18:287-330.

10. Rosenow, E. G. III, and D. T. Carr. 1979. Bronchogenic carcinoma. Cancer (Phila.). 29:233-245.

11. Baylin, S. B., R. D. Jackson, G. Goodwin, and A. F. Gazdar. 1982. Neuroendocrine related biochemistry in the spectrum of human lung cancers. Exp. Lung. Res. 3:209-223.

12. Rozengurt, E., and J. Sinnett-Smith. 1983. Bombesin stimulation of DNA synthesis and cell division in cultures of Swiss 3T3 cells. Proc. Natl. Acad. Sci. USA. 80:2936-2940.

13. Yamaguchi, K., K. Abe, T. Kameya, I. Adachi, S. Taguchi, and K. Otsubo. 1983. Production and molecular size heterogeneity of immunoreactive gastrin releasing peptide in fetal and adult lungs and primary lung tumors. Cancer Res. 43:3932-3939.

14. Kaplan, P. L., and B. Ozanne. 1983. Cellular responsiveness to growth factors correlates with a cell's ability to express the transformed phenotype. Cell. 33:931-938.

15. Pathak, M. A., L. M. Matrisian, B. E. Magun, and S. E. Salmon. 1982. Effect of epidermal growth factor on clonogenic growth of primary human tumor cells. Int. J. Cancer. 30:745-750.

16. Kawamoto, T., J. D. Sato, A. Le, J. Polikoff, G. H. Sato, and J. Mendelsohn. 1983. Growth stimulation of A431 cells by epidermal growth factor. Proc. Natl. Acad. Sci. USA. 80:1337-1341.

17. Insel, P. A. 1978. Biochemistry and mode of action of hormones II. Int. Rev. Biochem. 20:1-43. 